\title{
'BeSAFE', effect-evaluation of internet-based, tailored safety information combined with personal counselling on parents' child safety behaviours: study design of a randomized controlled trial
}

\author{
Mirjam EJ van Beelen ${ }^{1 *}$, Tinneke MJ Beirens ${ }^{1}$, Mirjam K Struijk', Paul den Hertog ${ }^{2}$, Anke Oenema',
} Eduard F van Beeck', Hein Raat ${ }^{1}$

\begin{abstract}
Background: Injuries in or around the home are the most important cause of death among children aged 0-4 years old. It is also a major source of morbidity and loss of quality of life. In order to reduce the number of injuries, the Consumer Safety Institute introduced the use of Safety Information Leaflets in the Netherlands to provide safety education to parents of children aged 0-4 years. Despite current safety education, necessary safety behaviours are still not taken by a large number of parents, causing unnecessary risk of injury among young children. In an earlier study an E-health module with internet-based, tailored safety information was developed and applied. It concerns an advice for parents on safety behaviours in their homes regarding their child. The aim of this study is to evaluate the effect of this safety information combined with personal counselling on parents' child safety behaviours.

Methods/Design: Parents who are eligible for the regular well-child visit with their child at child age 5-8 months are invited to participate in this study. Participating parents are randomized into one of two groups: 1) internetbased, tailored safety information combined with personal counselling (intervention group), or 2) personal counselling using the Safety Information Leaflets of the Consumer Safety Institute in the Netherlands for children aged 12 to 24 months (control group). All parents receive safety information on safety topics regarding the prevention of falling, poisoning, drowning and burning. Parents of the intervention group will access the internetbased, tailored safety information module when their child is approximately 10 months old. After completion of the assessment questions, the program compiles a tailored safety advice. The parents are asked to devise and inscribe a personal implementation intention. During the next well-child visit, the Child Health Clinic professional will discuss this tailored safety information and the implementation intention with the parents. The control group will receive usual care, i.e. the provision of Safety Information Leaflets during their well-child visit at the child's age of 11 months.
\end{abstract}

Discussion: It is hypothesized that the intervention, internet-based, tailored safety information combined with personal counselling results in more parents' child safety behaviours.

Trial registration: Current Controlled Trials NTR1836

\footnotetext{
* Correspondence: m.vanbeelen@erasmusmc.nl

'Department of Public Health, Erasmus MC - University Medical Centre

Rotterdam, PO BOX 2040, 3000 CA Rotterdam, the Netherlands

Full list of author information is available at the end of the article
} 


\section{Background}

Injuries in or around the home are the most important cause of death among children aged 0-4 years old. It is also a major source of morbidity and loss of quality of life [1-3]. In the Netherlands each year 30 children aged $0-4$ years die caused by injuries in or around the home. Additionally 57.000 children aged 0-4 years are medically treated, of which 46.000 children at the emergency room of a hospital because of home injuries [4]. In order to reduce the number of injuries, the Consumer Safety Institute introduced the use of Safety Information Leaflets in the Netherlands to provide safety education to parents of children aged 0-4 years. These leaflets are well used in Child Health Clinics (CHC) and indications for a small effect on parental behaviours were gained through observational research $[5,6]$. However, despite current safety education, necessary safety behaviours are still not taken by a large number of parents, causing unnecessary risk of injury of young children. Improving the effectiveness of safety education to parents at CHC is therefore desirable. In an earlier study an E-health module with internet-based, tailored safety information was developed and applied. It concerns an internetbased, tailored information in combination with personal counselling for parents of infants on safety behaviours to be taken to the homes for their child [7-9]. In a process-evaluation it was found that majority of parents experience the new internet-based, tailored safety information as useful and applicable and that the $\mathrm{CHC}$ professionals are enthusiastic about the E-health module [8]. However there are no insights in the effects of the new internet-based, tailored safety information on parents' child safety behaviours compared to the current way of safety education.

\section{Objectives}

The objective of this study is to evaluate the effect of online, internet-based, tailored safety information combined with personal counselling on parents' child safety behaviours. Additionally a process evaluation will be conducted to provide insight in the feasibility of the intervention. In this article the design of the study is described.

\section{Study hypothesis}

The hypothesis of the study is that, after follow-up, parents of the intervention group show more safety behaviours regarding the prevention of falling, poisoning, drowning and burning compared to the control group. Furthermore we hypothesize that, determinants of safe behaviour, i.e. severity and self efficacy positively improve in the intervention group [10-14].

\section{Methods/design \\ Study design}

The study design is a randomized controlled trial (RCT), with a baseline measure point prior to the intervention and a follow-up measure point six months after the intervention. The course of the study with the specific items at each time point is described in table 1. Parents are individually randomized in an intervention group or a control group, according to a computerized random allocation generator. Parents had an equal probability of assignment to the groups. Parents of the intervention group receive internet-based, tailored safety information concerning the prevention of falling, poisoning, drowning and burning, combined with personal counselling at the $\mathrm{CHC}$. Parents of the control group receive 'care as usual', personal counselling at the $\mathrm{CHC}$ using the Safety Information Leaflets (children 12-24 months old) of the Consumer Safety Institute in the Netherlands, concerning the same four safety topics.

Data collection started in 2009 and will continue until 2011. This study is approved by the Medical Ethics Committee of Erasmus MC (MEC-2008-370).

\section{Study procedure and participants}

Parents who are eligible for the regular well-child visit with their child at child age 7.5 months receive written information about the study and are invited to provide informed consent to participate in the study. All parents receive a singular, personal code to $\log$ in at the website of the study (www.besafe-onderzoek.nl). In 2009, 90\% of all households in the Netherlands had access to the internet [15]. At the study website parents can find more information about the study and they can complete the questionnaires.

\section{Youth Health Care organisations and Child Health Clinic} teams

Managers of an opportunity sample of 26 Youth Health Care (YHC) organisations in the Netherlands were informed about the study and were contacted by the researchers to provide further information. Five YHC organisations in the provinces of Zuid-Holland, NoordBrabant and Zeeland volunteered to participate in the study, with a total of $30 \mathrm{CHC}$ teams. These teams cover both urban and rural regions in the Netherlands. Prior to the start of the study, the researchers arranged meetings to explain the procedure of the study and to instruct the participating $\mathrm{CHC}$ professionals.

\section{Children and their parents or caregivers}

The study population consists of parents or caregivers of toddlers (one per family). They are included in the study when their child is 5-8 months old and measurements continue until the child is circa 17 months old. Parents 
Table 1 Course BeSAFE study

\begin{tabular}{|c|c|c|}
\hline $\begin{array}{l}\text { Age of the } \\
\text { child }\end{array}$ & Intervention-group & Control-group \\
\hline $\begin{array}{l}5-8 \\
\text { months }\end{array}$ & $\begin{array}{l}\text { - Informing parents about the study } \\
\text { - Request for participation (max. } 2 \text { reminders) } \\
\text { - Information letter } \\
\text { - Information folder } \\
\text { - Questionnaire }\end{array}$ & $\begin{array}{l}\text { - Informing parents about the study } \\
\text { - Request for participation (max. } 2 \\
\text { reminders) } \\
\text { - Information letter } \\
\text { - Information folder } \\
\text { - Questionnaire }\end{array}$ \\
\hline $\begin{array}{l}5-8 \\
\text { months }\end{array}$ & $\begin{array}{l}\text { - Parents log in on the website } \\
\text { - Parents provide informed consent } \\
\text { - Parents complete the Baseline Questionnaire }\end{array}$ & $\begin{array}{l}\text { - Parents log in on the website } \\
\text { - Parents provide informed consent } \\
\text { - Parents complete the Baseline } \\
\text { Questionnaire }\end{array}$ \\
\hline
\end{tabular}

Randomization in intervention or control group

10 Parents are invited through e-mail to complete the online, internet-based, tailored safety

months information questionnaire (max. 2 reminders)

11

months

Well-child visit

- Personal counselling to discuss the internet-based, tailored safety information and implementation-intention plan

- Complete process-evaluation form by parents

- Complete process-evaluation form by Child Health Care professional

12 Repeating the internet-based, tailored safety information and implementation

months intention, send to the parent by e-mail

$17 \quad$ Follow-up questionnaire

months Follow up questionnaire send to the parent (max. 2 reminders)
Well-child visit

- Usual Care: Safety Information Leaflets of children in the age range of this study have a high attendance percentage $(90 \%)$ at Child Health Clinics [15].

Only parents who understand the Dutch language and have access to the internet are eligible to be included in the study. The study design and participant flow are shown in Figure 1.

\section{Intervention}

The BeSAFE intervention aims at 4 major topics on safety in or around the home of children aged 12 to 24 months; prevention of falling, poisoning, drowning and burning [5,8,16-22]. The different components of the safety topics of the intervention can be found in table 2 . The intervention is based on the social ecological model, where safety and health are influenced by a combination of environment (in and around the home) and personal factors (the parents) and the interaction between them [23]. Parents are the most important mediators of the environment of these young and vulnerable children. Parents influence both the physical environment as the social environment of the child, mediated by the parenting style and specific parenting practices [24-27]. Therefore interventions should be aimed at the parents to guarantee the safety and health of the young child. Determinants of parents' behaviours can be found in the Protection Motivation Theory (PMT) and the theory of planned behaviour and includes severity, vulnerability, response efficacy, self efficacy and intentions [10,12-14].

The BeSAFE intervention consists of internet-based, tailored safety information combined with personal counselling at the $\mathrm{CHC}$. The BeSAFE intervention module consists of a questionnaire assessing ten specific parents' child safety behaviours in the prevention of falling, poisoning, drowning and burning and determinants of safety behaviour (intentions, possible barriers and self efficacy); a library of safety messages; and algorithm to compose tailored health information for the parent [28]. Parents who give informed consent and fill in the baseline questionnaire receive an e-mail, when their child is about 10 months old, inviting them to participate in the BeSAFE intervention. As a first step parents complete a questionnaire, which is used to generate an online tailored safety advice. When parents have read their personal advice, they are invited to devise and inscribe an implementation intention. In this implementation intention parents plan specific actions for improving their 




safety behaviour and implementing them in their home situation at a specified time $[29,30]$. It consists of three parts, i.e. what, when and where. The safety information and implementation intention of each parent will be sent by e-mail to both the parent and the $\mathrm{CHC}$ professional, in order to prepare them for the well-child visit at 11 months. At the well-child visit the $\mathrm{CHC}$ professional will discuss the safety information and the implementation intention with the parent, using the techniques of motivational interviewing (MI). Motivational interviewing is believed to represent a brief and effective method for addressing behaviour change. Positive attitudes and experienced barriers of the parents are discussed in order to improve parents' child safety behaviours. One aspect of this motivational interviewing is giving attention to transforming positive intention into real behaviour [29-31]. CHC professionals were trained to apply motivational interviewing. Approximately four weeks after the well-child visit parents receive a reminder of their safety information and the implementation intention in order to strengthen the message.

\section{Control}

The control group will receive care us usual; i.e. parents receive a Safety Information Leaflet (for children aged 12-24 months) of the Consumer Safety Institute during their $\mathrm{CHC}$ visit at the child age of approximately 11 months [6,21,22,32]. The Safety Information Leaflets contain relevant information about the prevention of injuries of toddlers in or around the home, divided in 
Table 2 Safety advices of the intervention based on safety behaviour in and around the home

\begin{tabular}{|c|c|c|}
\hline $\begin{array}{l}\text { Safety behaviour } \\
\text { concerning the } \\
\text { prevention of }\end{array}$ & Applicable if: & Reinforcement or NO information when: \\
\hline \multicolumn{3}{|l|}{ Falling } \\
\hline - Stair gate & - The house has a staircase which the child can reach & - A stair gate is present en is being used at all times \\
\hline - Balcony & - The house has a balcony & - The child is never left alone on the balcony \\
\hline \multicolumn{3}{|l|}{ Poisoning } \\
\hline - Cleaning products & - Always & - Stored in a closet with a lock or higher than 1.50 meters \\
\hline - Medicines & - Always & - Stored in a closet with a lock or higher than 1.50 meters \\
\hline \multicolumn{3}{|l|}{ Drowning } \\
\hline - Bath tub & - The child takes a bath & - Never left alone in the bath tub \\
\hline - Swimming pool & - The child swims in the swimming pool & - Never left alone in the swimming pool \\
\hline - Pond & - There is a pond in the garden & - Always the information to fill up the pond \\
\hline \multicolumn{3}{|l|}{ Burns } \\
\hline - Thermostat-controlled tap & - Always & - Thermostat-controlled tap present \\
\hline - Hot drinks & - Always & - Child never on parents womb when drinking hot drinks \\
\hline - Kitchen & - Always & - Child never in the kitchen when cooking \\
\hline
\end{tabular}

general information and safety advices about the prevention of falling (i.e. window protection, stair gates, practice walking down the stairs), poisoning (i.e. safe storage of cleaning products and medicines), drowning (i.e. ponds) and burning (i.e. hot fluids, hot pans) [22].

\section{Measurements}

\section{Primary outcome measures}

The primary outcomes of the study are parents' child safety behaviours measured at the child's age of 17 months, regarding the prevention of falling, poisoning, drowning and burning, i.e. presence and use of stair gates, never leaving the child alone on the balcony, safe storage of cleaning products and medicines, never leaving the child alone in the bath tub, safety of a swimming pool or a pond in the garden, thermostat controlled taps, drinking hot fluids while the child is on the parent's lap and keeping the child out of the kitchen while the parents is cooking. In the questionnaires parents are asked which safety behaviours they take in their homes. Some behaviours are only assessed when they are applicable to the situation of the parent. For example, when there are no stairs in the homes, no questions about installing stair gates will be asked.

Presence of safety measures, i.e. stair gate or thermostatic controlled taps is defined as present/not present. Safety behaviour, i.e. closing the stair gate, storing cleaning products after use and drinking hot fluids with a child on parent's lap is scored on a five-point scale from 'never' to 'always'.

\section{Secondary outcome measures}

The secondary outcomes are the determinants of the above mentioned parents' child safety behaviours, i.e. severity, vulnerability, response efficacy, self efficacy and intentions. Secondary outcomes, except intentions, are measured on five-point Likert scales.

Severity is measured with one item per safety measure, asking how seriously they perceived the consequences of this event (from not serious at all to very serious). Vulnerability is measured by asking respondents their perception of their child's risk of an unintentional injury on each specific subject (from low risk to high risk).

Response efficacy is assessed by asking how helpful parents perceived the specific behaviour to be for preventing an injury (from very helpful to not very helpful).

Self efficacy is measured by asking parents how difficult or easy they perceive taking the safety measures to be (from very easy to very difficult).

Intentions are assessed by asking whether the parent intends to take the specific safety measure. Answers to be given are yes, within one month; yes, within one to six months, yes, but not within six months; or no intention.

\section{Baseline questionnaire}

The baseline questionnaire, completed at child age of circa 7, 5 months, consists of questions on pregnancy, birth, gender, ethnicity of the child and the parents, educational level of the parents, household and family composition, the ten specific parents' child safety behaviours (presence and use of stair gates, never leaving the 
child alone on the balcony, safe storage of cleaning products and medicines, never leaving the child alone in the bath tub, safety of a swimming pool or a pond in the garden, thermostat controlled taps, drinking hot fluids while the child is on the parent's lap and keeping the child out of the kitchen while the parents is cooking) and the determinants of these safety behaviours (severity, vulnerability, response efficacy, self efficacy and intentions).

\section{Follow-up questionnaire}

When the child is approximately 17 months old, 6 months after the intervention, all participating parents will receive a follow-up questionnaire. This questionnaire contains the same items on safety behaviours and the determinants of these safety behaviours.

\section{Process-evaluation}

In addition to the effect-evaluation a process-evaluation will be carried out. All parents who use the BeSAFE intervention module are asked to answer a few evaluating questions about the programme, i.e. which part of the advice parents have read, what there opinion is about the advice, do parents intend to change anything in there behaviour after reading the advice and what they think about the time they needed to complete the module. All parents in the intervention group and $\mathrm{CHC}$ professionals who provide the intervention will be asked to complete a process-evaluation form after the wellchild visit at 11 months where the tailored safety information is discussed. It consists of questions regarding the feasibility of the intervention within the well-child visit, the perceived usefulness of the intervention and the discussed items during the well-child visit.

\section{Power of the study}

We will calculate sum scores of parents' child safety behaviours (0-10 points) of all participating parents, at follow-up as well as at baseline. Power calculations showed that a total number of 1200 parents are needed to detect a difference of 0.34 points between intervention and control group, assuming a mean score of 3.5 points and a standard deviation of 1.7 points, with a power of 0.80 and alpha 0.05 . Assuming a participation of $50 \%$ and a loss-to-follow-up of $30 \%$, we will have complete data at follow-up form 840 parents (420 in both the intervention and control group).

Considering the dichotomous outcome measures of 'stair gate present' we assume an unsafe situation in 30\% of families in the control group [8]. A difference of $9 \%$ between the percentages unsafe families of the intervention group and the control group can be shown $(21 \%$ in the intervention group, $30 \%$ in the control group).
Considering the dichotomous outcome measures of 'safe storage of cleaning products' we assume an unsafe situation in $20 \%$ of families in the control group [33]. A difference of $8 \%$ between the percentages unsafe families of the intervention group and the control group can be shown (12\% in the intervention group, $20 \%$ in the control group).

\section{Statistical analyses}

Statistical analyses are performed using SPSS 16.0 (SPSS Inc., Chigaco, IL.)

Descriptive statistics are used to describe parents and child characteristics and variable scores (behaviours) for the intervention and control group at baseline and follow-up.

\section{Effect-evaluation}

The aim of the study is to assess the effect of internetbased, tailored safety information combined with personal counselling on parents' child safety behaviours. An intention-to-treat analysis will be applied [34]. Regression analysis will be used to evaluate continuous outcome (sum scores) variables, with group (intervention or control group) as independent variable and the baseline values as covariates. Logistic regression analysis will be performed for the evaluation of dichotomous outcomes. Additionally effect modification by composition of the family (one versus two children), educational level and ethnicity of the parents will be explored.

\section{Process-evaluation}

In addition to the effect-evaluation a process-evaluation will be carried out. Adherence of both the $\mathrm{CHC}$ professionals and parents to the different elements of the BeSAFE intervention will be evaluated [35].

\section{Discussion}

This article describes the design of a randomised controlled trial regarding the BeSAFE intervention intended to promote parents' child safety behaviours. The study evaluates the effect of internet-based, tailored safety information combined with personal counselling on parents' child safety behaviours. We want to look at parents' child safety behaviours and want to compare these behaviours between the intervention and the control group. The new elements which are applied in the intervention group include a tailored safety advice for the parent, an implementation intention filled in by the parent and the discussion of this advice and implementation intention by the $\mathrm{CHC}$ professional with the parents using the techniques of motivational interviewing.

It is hypothesized that after 6 months of follow-up, parents in the intervention group show more child safety behaviour regarding the prevention of falling, poisoning, drowning and burning. Differences between 
subgroups (ethnicity and socio-economic status) regarding the effects of the intervention will be explored.

Strengths of the study are the power of the study, the randomized controlled design, and providing the intervention in daily practice of the $\mathrm{CHC}$, which have a high attendance. The follow-up at 6 months allows investigating the effect of the intervention within an appropriate time schedule in the development of the child. Regarding the generalisability of the study results there can be noticed that it is a randomized controlled study conducted in the practice setting. The intervention is applicable in daily practice of the $\mathrm{CHC}$ professional, which will facilitate the implementation of the internetbased, tailored safety information if it is found effective. The data will be collected in both rural and urban areas of the Netherlands, resulting in higher generalisability.

Because the study relies on self-report by parents, misclassification might occur. Parents might give socially desirable answers by overstating their safety behaviours. A limitation of the study to be addressed includes the questionnaire and intervention being available in Dutch only. For this reason it is likely that only parents who master the Dutch language will participate in the study.

In conclusion, this study evaluates the effect of internet-based, tailored safety for parents of young children, combined with personal counselling at the Child Health Clinic.

\section{Acknowledgements}

This study is funded by a grant from ZonMw (project no. 50-50205-9825028000)

Study website

http://www.besafe-onderzoek.nl

\section{Author details}

'Department of Public Health, Erasmus MC - University Medical Centre Rotterdam, PO BOX 2040, 3000 CA Rotterdam, the Netherlands. ${ }^{2}$ Consumer Safety Institute, PO BOX 75169, 1070 AD Amsterdam, the Netherlands.

\section{Authors' contributions}

HR had the original idea for the study and its design, and was responsible for acquiring the study grant. MB is responsible for the data collection, data analysis and reporting of the study results. MS helps coordinate the study and participates in data collection.

$E B, P H, M S, T B$ and $A O$ provide expert input during the study. $H R$ and $T B$ supervise the study. All authors regularly participated in discussing the design and protocols used in the study. All authors read and approved the final manuscript.

\section{Competing interests}

The authors declare that they have no competing interests.

Received: 29 July 2010 Accepted: 9 August 2010

Published: 9 August 2010

\section{References}

1. Peden M, Oyegbite K, Ozanne-Smith J, Hyder AA, Branche C, Fazlur Rahman AKM, Rivara F, Bartolomeos K: World report on child injury prevention. Geneva: WHO 2008.
2. Polinder S, Haagsma JA, Toet H, Brugmans MJ, van Beeck EF: Burden of injury in childhood and adolescence in 8 European countries. BMC public health 2010, 10:45.

3. Polinder $\mathrm{S}$, Meerding WJ, Toet $H$, Mulder S, Essink-Bot ML, van Beeck EF: Prevalence and prognostic factors of disability after childhood injury. Pediatrics 2005, 116(6):e810-817.

4. Consument en Veiligheid: Letsel Informatie Systeem (LIS) [Dutch Injury Surveillance System]. Amsterdam 2003.

5. van der Burg-Beijk P: Veiligheidskaarten, een waardevol hulpmiddel [Safety information leaflets, a valuable resource]. T Jeugdgezondheidszorg 1990, 67-68.

6. Factsheet 4: Onderzoek naar de effectiviteit van de veiligheidsinformatiekaarten [Factsheet 4: Study of the effectiveness of the safety information leaflets]. Amsterdam: Consument en Veiligheid 2007.

7. Mangunkusumo R, Brug J, Duisterhout J, de Koning H, Raat H: Feasibility, acceptability, and quality of Internet-administered adolescent health promotion in a preventive-care setting. Health Educ Res 2007, 22(1):1-13.

8. Kloek $\mathrm{G}$, Raat $\mathrm{H}$ : Het begin van gezond leven; Interactief Advies-op-Maat voor ouders van jonge kinderen in combinatie met persoonlijke advisering op het Consultatiebureau [Interactive tailored advice for parents of young children combined with personal advice at the Child Health Clinic]. Rapport. Rotterdam: Afdeling Maatschappelijke gezondheidszorg. Erasmus MC - Universitair Medisch Centrum Rotterdam 2007.

9. Mangunkusumo RT, Brug J, de Koning HJ, van der Lei J, Raat H: Schoolbased internet-tailored fruit and vegetable education combined with brief counselling increases children's awareness of intake levels. Public Health Nutr 2007, 10(3):273-279.

10. Ajzen I, Madden TJ: Prediction of goal-directed behavior: Attitudes, intentions, and perceived behavioral control. Journal of Experimental Social Psychology 1986, 22(5):453-474.

11. Bandura A: Social Foundation for Thought and Action: a Social Cognitive Theory Englewood Cliffs, NJ: Prentice Hall 1986.

12. Beirens TMJ, Brug J, van Beeck EF, Dekker R, den Hertog P, Raat H: Assessing psychosocial correlates of parental safety behaviour using Protection Motivation Theory: stair gate presence and use among parents of toddlers. Health Educ Res 2008, 23(4):723-731.

13. McGuire W: The Handbook of social psychology New York: Random House 1985.

14. Rogers R: Protection Motivation Theorie New York: Plenum Press 1997.

15. Centraal Bureau voor de statistiek [Statistics Netherlands]. [http://www. cbs.nl].

16. Nansel TR, Weaver $N$, Donlin $M$, Jacobsen $H$, Kreuter MW, Simons-Morton B: Baby, Be Safe: the effect of tailored communications for pediatric injury prevention provided in a primary care setting. Patient Educ Couns 2002, 46(3):175-190.

17. Kendrick D, Barlow J, Hampshire A, Polnay L, Stewart-Brown S: Parenting interventions for the prevention of unintentional injuries in childhood. Cochrane Database Syst Rev 2007, , 4: CD006020.

18. Kendrick D, Coupland C, Mulvaney C, Simpson J, Smith SJ, Sutton A Watson M, Woods A: Home safety education and provision of safety equipment for injury prevention. Cochrane Database Syst Rev 2007, , 1 : CD005014.

19. The Injury prevention program. [http://www.aap.org/FAMILY/tippmain. htm].

20. Gielen AC, Wilson ME, McDonald EM, Serwint JR, Andrews JS, Hwang WT Wang MC: Randomized trial of enhanced anticipatory guidance for injury prevention. Arch Pediatr Adolesc Med 2001, 155(1):42-49.

21. Protocol Veilig groot worden, Methodiek Veiligheidsinformatiekaarten [Protocol growing up safe, methodology safety information leaflets]. Amsterdam: Stichting Consument en Veiligheid 2007.

22. Veilig groot worden; veiligheidskaarten voor kinderen van 0-6 maanden, 6-12 maanden, 1-2 jaar, 2-4 jaar [Growing up safe; safety information leaflets for children aged 0-6 months, 6-12 months, 1-2 years, 2-1 years]. Amsterdam: Stichting Consument en Veiligheid 2002

23. Green LW, Richard L, Potvin L: Ecological foundations of health promotion. Am J Health Promot 1996, 10(4):270-281.

24. Darling N, Steinberg L: Parenting Style as Context - an Ingetrative Model. Psych Bull 1993, 113:487-496. 
25. Dekovic M, Janssens JMAM, Gerris JRM: Factor structure and construct validity of the Block Child Rearing Practices Report (CRPR). Psych Assessment 1991, 3:182-187.

26. Sanders MR, Markie-Dadds C, Turner MT: Theoretical, scientific and clinical foundations of the Triple P-Positive Parenting Program. Parenting research and practice monograph 1 2003, 1-24.

27. van der Horst K, Kremers S, Ferreira I, Singh A, Oenema A, Brug J: Perceived parenting style and practices and the consumption of sugar-sweetened beverages by adolescents. Health Educ Res 2007, 22(2):295-304.

28. Kreuter MW, Farrell DW, Olevitch LR, Brennan LK: Tailoring Health Messages: Customizing Communication With Computer Technology. Lawrence Erlbaum Ass Mahwah, NJ 2000

29. Sheeran P: Intention-Behavior Ralations: A conceptual and Empirical Review. European Review of Social Psychology 2002, 12:1-36.

30. Sheeran $P$, Silverman M: Evaluation of three interventions to promote workplace health and safety: evidence for the utility of implementation intentions. Soc Sci Med 2003, 56(10):2153-2163.

31. Sindelar HA, Abrantes AM, Hart C, Lewander W, Spirito A: Motivational interviewing in pediatric practice. Curr Probl Pediatr Adolesc Health Care 2004, 34(9):322-339.

32. Basistakenpakket Jeugdgezondheidszorg 0-19 jaar [Youth Health Care Tasks 0-19 years]. Ministerie van Volksgezondheid, Welzijn en Sport 2002

33. Beirens TMJ, van Beeck EF, Dekker R, Brug J, Raat H: Unsafe storage of poisons in homes with toddlers. Accident Analysis \& Prevention 2006, 38(4):772-776.

34. Hollis $\mathrm{S}$, Campbell $\mathrm{F}$ : What is meant by intention to treat analysis? Survey of published randomised controlled trials. BMJ 1999, 319(7211):670-674.

35. Pope C, Mays N: Reaching the parts other methods cannot reach: an introduction to qualitative methods in health and health services research. BMJ 1995, 311(6996):42-45.

\section{Pre-publication history}

The pre-publication history for this paper can be accessed here: http://www.biomedcentral.com/1471-2458/10/466/prepub

doi:10.1186/1471-2458-10-466

Cite this article as: van Beelen et al:: 'BeSAFE', effect-evaluation of internet-based, tailored safety information combined with personal counselling on parents' child safety behaviours: study design of a randomized controlled trial. BMC Public Health 2010 10:466.

\section{Submit your next manuscript to BioMed Central and take full advantage of:}

- Convenient online submission

- Thorough peer review

- No space constraints or color figure charges

- Immediate publication on acceptance

- Inclusion in PubMed, CAS, Scopus and Google Scholar

- Research which is freely available for redistribution

Submit your manuscript at www.biomedcentral.com/submit
Biomed Central 